\title{
Use of metformin and vildagliptin for treatment of type 2 diabetes in the elderly
}

This article was published in the following Dove Press journal:

Drug Design, Development and Therapy

18 June 2014

Number of times this article has been viewed

\author{
Antoni Sicras-Mainar ${ }^{1}$ \\ Ruth Navarro-Artieda ${ }^{2}$ \\ 'Dirección de Planificación, \\ Badalona Serveis Assistencials \\ SA, ${ }^{2}$ Documentación Médica, \\ Hospital Germans Trias i Pujol, \\ Badalona, Barcelona, Spain
}

Correspondence: Antoni Sicras-Mainar Dirección de Planificación y Desarrollo Organizativo, C Gaietà Soler, 6-8 entlo, Badalona 089II, Barcelona, Spain

Tel +935072684

Email asicras@bsa.cat
Background: The aim of this study was to describe the clinical (treatment adherence, metabolic control, hypoglycemia, and macrovascular complications) and economic (resource use and costs) consequences of using a combination of metformin + vildagliptin to treat type 2 diabetes in elderly patients seen in daily clinical practice.

Methods: We conducted a multicenter, retrospective, observational study that included patients aged $\geq 65$ years treated with metformin who started a second oral antidiabetic therapy during the years 2008-2009. There were two groups of patients: a study group receiving metformin + vildagliptin and a reference group receiving metformin + other oral antidiabetics (sulfonylureas or glitazones). The main measures were comorbidity, compliance/persistence, metabolic control (glycosylated hemoglobin $<7 \%$ ), complications (hypoglycemic, macrovascular), and total costs. The patients were followed for 2 years.

Results: We recruited 987 patients (49.1\% male) of mean age 74.2 years. There were $270(27.4 \%)$ patients in the metformin + vildagliptin group and $717(72.6 \%)$ in the reference group. Vildagliptin-treated patients had significantly $(P<0.05)$ improved compliance $(68.3 \%$ versus $62.5 \%$, respectively), persistence (61.5\% versus $55.1 \%)$, and metabolic control $(63.3 \%$ versus $57.6 \%)$. They also had lower rates of hypoglycemia (17.4\% versus $42.8 \%$ ) and cardiovascular events (4.4\% versus 8.6\%) and lower total costs (€2,544 versus $€ 2,699, P<0.05)$.

Conclusion: Patients treated with metformin and vildagliptin showed better adherence and metabolic control and lower rates of hypoglycemia, resulting in lower health care costs for the national health system.

Keywords: vildagliptin, diabetes, metabolic control, hypoglycemia, cardiovascular events, health costs

\section{Introduction}

Cardiovascular disease is the leading cause of morbidity and mortality in developed countries. ${ }^{1}$ Type 2 diabetes mellitus (T2DM) is one of the diseases with the greatest public health impact, not only due to its high frequency but also because of its acute and chronic complications, the high rate of associated morbidity and mortality, and the impact on quality of life, all of which result in high use of health care resources, especially in elderly patients. ${ }^{2,3}$ In Spain, the prevalence of T2DM is $8 \%$ in females and $12 \%$ in males, with fluctuations of $6 \%-12 \%$ in different studies. ${ }^{4,5}$

The aim of drug treatment for T2DM is to achieve optimal metabolic control with maximum safety. Metformin is recommended as the first therapeutic choice together with dietary measures. ${ }^{6,7}$ When metabolic control is not achieved, addition of a second drug is recommended as combination therapy. ${ }^{8,9}$ The most frequent acute complication 
of diabetes is hypoglycemia, particularly in patients treated with insulin and/or sulfonylureas. ${ }^{6,-11}$ Dipeptidyl peptidase-4 (DPP-4) inhibitors, such as vildagliptin, have an advantage over traditional secretagogues in that they significantly reduce hypoglycemia because their insulin secretion stimulating mechanism is glucose-dependent. ${ }^{7,12}$

The available evidence in clinical practice in Spain regarding the clinical and economic effects in older patients on oral antidiabetics is limited or nonexistent. The aim of this study was to compare the clinical (compliance/persistence with treatment, metabolic control, hypoglycemia, and macrovascular complications) and economic (resource use and health care costs) implications of a combination of metformin + vildagliptin versus a combination of metformin + other oral antidiabetics in T2DM patients aged $\geq 65$ years.

\section{Materials and methods Design and study population}

In this observational, longitudinal, multicenter study, we reviewed the computerized medical records of outpatients and inpatients treated with metformin. The study population consisted of patients attending six primary care centers managed by Badalona Serveis Assistencials SA. Information on health resources was obtained from two reference hospitals.

\section{Inclusion and exclusion criteria}

The study included all patients who started a second antidiabetic treatment between January 1, 2008, and December 31, 2009 , and fulfilled the following conditions: age $\geq 65$ years; diagnosis of T2DM for at least 2 years before the start of the study; following the cardiovascular risk protocol/guidelines of the participating centers; participating in the chronic prescription program for obtaining medical prescriptions (with a register of the daily dose and interval of time and duration of each treatment administered); metformin monotherapy as the first treatment option; and availability for progress to be monitored during the 2-year study period. Subjects transferring from other municipalities or regions and patients receiving insulin were excluded. There were two study groups, ie, a study group treated with metformin + vildagliptin and a reference group treated with metformin + other oral antidiabetics.

\section{Measurement of diabetes and complications}

Diagnosis of T2DM was made according to the International Classification of Primary Care ${ }^{13}$ and from the coding of hospital and emergency room discharges using the International Classification of Diseases, 9th Revision, Clinical Modification (ICD-9-CM). Baseline data were obtained on microvascular complications, ie, diabetic retinopathy, diabetic nephropathy, diabetic neuropathy, and diabetic vasculopathy. We also identified all cases of symptomatic hypoglycemia.

Macrovascular complications and cardiovascular events included: heart disease, including cardiac ischemia, acute myocardial infarction, and heart failure, as defined by the World Health Organization diagnostic criteria; cerebrovascular disease, including stroke (ischemic or hemorrhagic, according to the American Heart Association) ${ }^{7}$ and transient ischemic attack; all types of peripheral arterial disease; and renal disease (diabetic nephropathy or impaired renal function [serum creatinine $>133 \mathrm{mmol}$ in males or $>124 \mathrm{mmol}$ in females, or glomerular filtration rate $<60 \mathrm{~mL}$ per minute]). Applications laboratory and test performance creatinine or glomerular filtration rate $<60 \mathrm{~mL}$ per minute. Laboratory results are captured at all centers of the organization as part of integrated information systems. The cumulative incidence rate was defined as the proportion of healthy individuals who developed a complication (number of new cases).

\section{Compliance and persistence with treatment and metabolic control}

Information was collected on the following oral antidiabetics according to the Anatomical Therapeutic Chemical Classification System: ${ }^{14}$ metformin (A10BA*); insulin release stimulators, ie, sulfonylureas $(\mathrm{A} 10 \mathrm{BB} *)$ and glinides $\left(\mathrm{A} 10 \mathrm{BX}^{*}\right)$; glitazones $\left(\mathrm{A} 10 \mathrm{BG}^{*}\right)$; and vildagliptin in monotherapy or in combination. We did not include patients receiving alpha-glucosidase inhibitors due to insufficient patient numbers. Compliance during the study period was calculated by dividing the total number of tablets dispensed by those recommended or prescribed. Treatment persistence was defined as the time, measured in months, without abandoning the initial treatment or with no change to another medication for at least 30 days after the initial prescription. Metabolic control was assessed by glycosylated hemoglobin $\left(\mathrm{HbA}_{1 \mathrm{c}}\right)$ levels $<7 \%$. $^{6}$

\section{Sociodemographic and comorbidity variables}

The general comorbidity summary variables used for each treated patient were: the Charlson comorbidity index, ${ }^{15}$ which is used as a proxy for health status, and the individual 
causality index, obtained from Adjusted Clinical Groups, which is a patient classification system based on isoresource use. ${ }^{16}$ The Adjusted Clinical Groups application provides resource utilization bands, with each patient placed in one of five mutually exclusive categories, according to general morbidity: 1 (healthy or very low morbidity); 2 (low morbidity); 3 (moderate morbidity); 4 (high morbidity); and 5 (very high morbidity).

\section{Resource use and cost model}

Direct health care costs were defined as costs related to medical care. The unit costs used in the study are in $2011 €$. The tariffs were obtained from the cost accounting system used at each center, except for medications (retail price), as follows: medical visit in primary health care, $€ 23.19$; medical visit in the emergency room, $€ 117.53$; hospitalization for one day, $€ 320.90$; specialist medical visit, $€ 104.41$; laboratory tests, €22.30; conventional radiology, €18.50; diagnostic/ therapeutic tests, $€ 37.12$; and drug prescriptions (retail price includes value-added tax).

\section{Statistical analysis}

A descriptive univariate analysis was performed, expressing values as the mean, standard deviation, and $95 \%$ confidence interval (CI). The normality of the distribution of quantitative variables was verified using the Kolmogorov-Smirnov test. In the bivariate analysis, we used analysis of variance, the chi-square test, Pearson's chi-squared test, and the MannWhitney-Wilcoxon nonparametric test. A logistic regression analysis was performed to determine the variables associated with CVE (cardiovascular events [presence/absence]) using an enter procedure (Wald statistic). The comparison of costs was done according to the recommendations of Thompson and Barber $^{17}$ using analysis of covariance, with sex, age, resource utilization band, Charlson comorbidity index, and time of evolution as covariates.

\section{Results}

Of the 10,477 subjects aged $\geq 65$ years assigned to and attending the study centers regularly, 9,876 sought attention and 1,899 were diagnosed with T2DM (prevalence 19.2\%; 95\% CI 17.4-21.0). Of these, 700 patients were excluded for the following reasons: 151 received no drug treatment, 63 received other drug therapies, 40 discontinued treatment, treatment was modified in 299 during follow-up, 103 were lost to follow-up, and 44 were lost for unknown reasons and/or other causes. The percentage distribution of patients excluded was similar in the two study groups.
Therefore, 987 patients receiving combination therapy were included in the study: $27.4 \%(n=270)$ in the study group were treated with vildagliptin and $72.6 \%(n=717)$ in the reference group were treated with sulfonylureas $(82.5 \%)$ or glitazones (17.5\%). Table 1 shows the baseline characteristics of patients included by treatment group. The overall mean age was $74.2 \pm 6.2$ years and $49.1 \%$ were male. Mean age and general comorbidity was similar between the study group and the reference group (73.6 years versus 74.4 years and 5.7 diagnoses versus 5.8 diagnoses, respectively).

Vildagliptin-treated patients showed better compliance (68.3\% versus $62.5 \%, P=0.002)$ and persistence $(61.5 \%$ versus $55.1 \%, P=0.031$ ) with therapy (Table 2 ). There was an acceptable correlation between degree of compliance and months of treatment persistence $(r=0.541, P<0.001)$. Metabolic control $\left(\mathrm{HbA}_{1 \mathrm{c}}<7 \%\right)$ of T2DM at the end of follow-up was better in vildagliptin-treated patients $(63.3 \%$ versus $57.6 \%$ respectively, $P=0.022$ ). In the logistic model, vildagliptin-treated patients showed better therapeutic compliance (odds ratio 1.2, 95\% CI 1.1-1.4, $P=0.013$ ), treatment persistence (odds ratio $1.1,95 \%$ CI $1.0-1.2, P=0.032$ ), and metabolic control (odds ratio 1.4, 95\% CI 1.2-1.6, $P=0.038)$.

Vildagliptin-treated patients had fewer medical visits in primary care $(24.1$ versus $31.2, P<0.001)$ and hospital ( 1.9 versus $2.5, P=0.018$ ) than patients in the reference group. The gross and adjusted (covariates) cost models for the two groups during a follow-up of 2 years is shown in Table 3. The total cost for care of diabetic patients was 2.6 million Euros, of which $88.9 \%$ was spent on primary care and $11.1 \%$ was spent on specialized care. The gross mean unit costs for vildagliptin-treated patients were lower than those of the reference group ( $€ 2,518$ versus $€ 2,685$, respectively, $P=0.041$ ). The corrected costs (analysis of covariance) were $€ 2,544$ (95\% CI 2,385-2,703) in the vildagliptin-treated group and $€ 2,699$ (95\% CI $€ 2,602-2,796)$ in the reference group $(P=0.044)$. Health costs were moderately correlated with age $(r=0.335)$ and overall comorbidity (resource utilization band; $r=0.341, P<0.05)$.

Seventy-four patients experienced CVE $(7.5 \%, 95 \%$ CI 6.3-8.7). Vildagliptin-treated patients had a lower rate of CVE than the reference group $(4.4 \%$ versus $8.6 \%, P=0.025)$ and a lower proportion of new cases of ischemic heart disease ( $0.7 \%$ versus $2.1 \%, P=0.043)$, cerebrovascular accident (2.2\% versus $4.3 \%, P=0.042)$, and renal failure ( $1.5 \%$ versus $2.2 \%, P=0.138)$. The overall percentage of patients with hypoglycemia was $35.9 \%$. Vildagliptin-treated patients had a lower rate of hypoglycemia $(17.4 \%$ versus $42.8 \%, P<0.001)$. 
Table I Baseline characteristics of the study population

\begin{tabular}{|c|c|c|c|c|}
\hline \multirow{2}{*}{$\begin{array}{l}\text { Study groups } \\
\text { Patients, n (\%) }\end{array}$} & \multirow{2}{*}{$\begin{array}{l}\text { Metformin + OA } \\
n=717\end{array}$} & \multirow{2}{*}{$\begin{array}{l}\text { Metformin + vildagliptin } \\
\mathrm{n}=\mathbf{2 7 0}\end{array}$} & \multirow{2}{*}{$\begin{array}{l}\text { Total } \\
\mathrm{n}=987\end{array}$} & \multirow[t]{2}{*}{$P$-value } \\
\hline & & & & \\
\hline \multicolumn{5}{|l|}{ Sociodemographics } \\
\hline Mean age, years & $74.4(6.2)$ & $73.6(6.1)$ & $74.2(6.2)$ & 0.077 \\
\hline Sex (male) & $50.5 \%$ & $45.6 \%$ & $49.1 \%$ & 0.167 \\
\hline \multicolumn{5}{|l|}{ General comorbidity } \\
\hline Mean diagnoses & $5.8(2.5)$ & $5.7(2.3)$ & $5.8(2.5)$ & 0.488 \\
\hline Mean Charlson comorbidity index & I $(0.4)$ & I.I (0.5) & I.I $(0.4)$ & 0.296 \\
\hline Mean RUB & $3(0.6)$ & $3(0.5)$ & $3(0.6)$ & 0.574 \\
\hline RUB-I & $0.7 \%$ & $0.1 \%$ & $0.5 \%$ & \\
\hline RUB-2 & $12.2 \%$ & $10.1 \%$ & $11.6 \%$ & \\
\hline RUB-3 & $73.1 \%$ & $81.4 \%$ & $75.4 \%$ & \\
\hline RUB-4 & $12.4 \%$ & $7.2 \%$ & $11.0 \%$ & \\
\hline RUB-5 & $1.6 \%$ & $1.2 \%$ & $1.5 \%$ & 0.066 \\
\hline \multicolumn{5}{|l|}{ Comorbidities } \\
\hline Hypertension & $76.3 \%$ & $73.7 \%$ & $75.6 \%$ & 0.399 \\
\hline Dyslipidemia & $61.2 \%$ & $63.3 \%$ & $61.8 \%$ & 0.544 \\
\hline Obesity & $23.2 \%$ & $23.3 \%$ & $23.2 \%$ & 0.952 \\
\hline Active smoker & $14.2 \%$ & $15.2 \%$ & $14.5 \%$ & 0.703 \\
\hline Alcoholism & $2.5 \%$ & $2.6 \%$ & $2.5 \%$ & 0.942 \\
\hline Ischemic heart disease & $16.3 \%$ & $14.8 \%$ & $15.9 \%$ & 0.565 \\
\hline Cerebrovascular accident & $19.8 \%$ & $18.9 \%$ & $19.6 \%$ & 0.746 \\
\hline Cardiovascular event & $31.2 \%$ & $28.1 \%$ & $30.4 \%$ & 0.346 \\
\hline Organ failure & $20.2 \%$ & $21.9 \%$ & $20.7 \%$ & 0.573 \\
\hline Bronchial asthma & $5.6 \%$ & $3.3 \%$ & $5.0 \%$ & 0.148 \\
\hline COPD & $7.7 \%$ & $10.0 \%$ & $8.3 \%$ & 0.237 \\
\hline Neuropathies & $1.5 \%$ & $0.4 \%$ & $1.2 \%$ & 0.137 \\
\hline Dementia (all types) & $5.2 \%$ & $4.8 \%$ & $5.1 \%$ & 0.825 \\
\hline Depressive syndrome & $18.8 \%$ & $22.6 \%$ & $19.9 \%$ & 0.186 \\
\hline Malignant neoplasm & $13.5 \%$ & $11.9 \%$ & $13.1 \%$ & 0.486 \\
\hline \multicolumn{5}{|l|}{ Relationship with diabetes } \\
\hline Time since diagnosis, years & I $7.4(7.3)$ & $20(5.2)$ & I8.I (6.9) & 0.002 \\
\hline Diabetic retinopathy & $28.2 \%$ & $32.0 \%$ & $29.0 \%$ & 0.346 \\
\hline Diabetic neuropathy & $13.5 \%$ & $13.7 \%$ & $13.5 \%$ & 0.870 \\
\hline Diabetic nephropathy & $12.1 \%$ & $12.2 \%$ & $12.1 \%$ & 0.899 \\
\hline Change in glomerular filtration & $26.0 \%$ & $25.6 \%$ & $25.9 \%$ & 0.853 \\
\hline
\end{tabular}

Note: Values expressed as the percentage or mean (standard deviation).

Abbreviations: RUB, resource utilization band; COPD, chronic obstructive pulmonary disease; OA, oral antidiabetics, including sulfonylureas and glitazones.

In the logistic regression model, CVEs were associated with noncompliance with therapy (odds ratio 1.1, CI 1.0-1.3), metabolic control of T2DM (odds ratio 1.2, 95\% CI 1.1-1.4), male sex (odds ratio $1.4,95 \%$ CI $1.2-1.8$ ), and age (odds ratio $1.1,95 \% \mathrm{CI} 1.0-1.2, P<0.05)$. Overall, $0.8 \%$ of patients required hospitalizations, $3.5 \%$ were treated in the emergency department, and $44.6 \%$ were treated in primary care.

A subanalysis found no significant differences between patients treated with sulfonylureas and those treated with glitazones or between patients older and younger than 75 years. The proportions were maintained for all the variables analyzed.

\section{Discussion}

Our results show that elderly patients treated with a combination of metformin + vildagliptin had a lower rate of hypoglycemia and lower health costs than a reference group of patients receiving metformin and other oral antidiabetics. Scientific societies recommend addition of a DPP-4 inhibitor (gliptin) to metformin as an alternative to sulfonylureas, a glitazone, a glinide, or an $\alpha$-glucosidase inhibitor for the treatment of patients with T2DM who do not achieve metabolic control. ${ }^{18}$ This proportionality in treatment was maintained in this study. There remain uncertainties in the treatment of elderly patients with T2DM which have not been addressed in clinical trials. ${ }^{18,19}$

There are few published studies of compliance and persistence with oral antidiabetics and comparisons are difficult because of the different methodologies used; however, they show a compliance rate of $40 \%-80 \% .^{6-7,19,20}$ A recent study by Marquez et $\mathrm{al}^{21}$ found that one quarter of diabetic patients did 
Table 2 Compliance, persistence, and metabolic control according to the study groups

\begin{tabular}{|c|c|c|c|c|}
\hline Study groups & Metformin + OA & Metformin + vildagliptin & Total & $P$-value \\
\hline Patients, n (\%) & $n=717$ & $\mathbf{n}=\mathbf{2 7 0}$ & $n=987$ & \\
\hline Months on metformin & $29(14.2)$ & $25.9(12.1)$ & $28.1(13.7)$ & 0.002 \\
\hline Metformin use $>$ I year & $76.3 \%$ & $73.6 \%$ & $75.7 \%$ & $<0.001$ \\
\hline \multicolumn{5}{|l|}{ Months of associated treatment } \\
\hline Mean (SD) & $19.3(7.1)$ & $21.2(5.1)$ & $20.0(6.8)$ & $<0.001$ \\
\hline Median (P25-P75) & $21.0(10.0-23.0)$ & $22.0(17.0-24.0)$ & $22.0(13.0-23.0)$ & $<0.001$ \\
\hline Therapeutic compliance & $62.5 \%$ & $68.3 \%$ & $64.1 \%$ & 0.002 \\
\hline$\geq 80 \%$, high & $49.1 \%$ & $55.1 \%$ & $51.4 \%$ & \\
\hline $50 \%-79 \%$, medium & $30.7 \%$ & $29.1 \%$ & $30.3 \%$ & \\
\hline$<50 \%$, low & $20.2 \%$ & $15.8 \%$ & $18.2 \%$ & $<0.001$ \\
\hline Treatment persistence & $55.1 \%$ & $61.5 \%$ & $56.1 \%$ & 0.031 \\
\hline \multicolumn{5}{|l|}{ Metabolic control } \\
\hline Initial period & $55.7 \%$ & $58.8 \%$ & $56.5 \%$ & 0.360 \\
\hline Final period & $57.6 \%$ & $63.3 \%$ & $59.4 \%$ & \\
\hline Difference in percentages & $1.9 \%$ & $4.5 \%$ & $2.9 \%$ & 0.022 \\
\hline
\end{tabular}

Notes: Values expressed as a percentage or mean (standard deviation); treatment persistence was defined as the time without abandonment of initial treatment or with no change to other medication for at least 30 days after the initial prescription; metabolic control was defined as glycosylated hemoglobin $<7 \%$.

Abbreviations: OA, oral antidiabetics, includes sulfonylureas and glitazones; SD, standard deviation; P, percentile.

not comply with their treatment. A review by Cramer et $\mathrm{al}^{22}$ of 39 studies found that the rate of persistence at 12 months was $63 \%$ and compliance with oral antidiabetics was $58 \%$, and this was similar for all therapeutic classes analyzed. Jermendy et $\mathrm{a}^{23}$ studied patients receiving combination therapy with metformin and sulfonylureas and found a persistence of $56 \%$ at one year. This could be due to a random event (individual variability) or to the presence of unidentified confounding variables. However, one plausible explanation could be a better tolerability and safety profile, in particular because of significantly lower rates of hypoglycemia. ${ }^{6,8}$ Although more studies comparing the use of combination therapy are

Table 3 Model of gross and adjusted costs according to study group (mean unit cost in Euros) in the 2 year study period

\begin{tabular}{|c|c|c|c|c|}
\hline Study groups & Metformin + OA & Metformin + vildagliptin & Total & $P$-value \\
\hline Patients, n (\%) & $n=7 \mid 7$ & $n=\mathbf{2 7 0}$ & $n=987$ & \\
\hline \multicolumn{5}{|l|}{ Gross costs model } \\
\hline Primary care costs & $2,374.6(1,277.4)$ & $2,272(1,098.7)$ & $2,346.5(I, 23 I .4)$ & 0.244 \\
\hline Medical visits & $723.5(365.7)$ & $557.9(335.4)$ & $678.2(365.1)$ & $<0.001$ \\
\hline Laboratory tests & $70.1(40.3)$ & $51.2(31.6)$ & $64.9(39)$ & $<0.001$ \\
\hline Conventional radiology & $18.5(22.5)$ & $20.6(24)$ & 19.1 (22.9) & 0.189 \\
\hline Complementary tests & $17.4(28.4)$ & $17.3(25.7)$ & $17.4(27.7)$ & 0.950 \\
\hline Drug costs (total) & I,545.I (I,087.4) & I,625 (946.4) & I,566.9 (I,050.8) & 0.287 \\
\hline Metformin & $598.9(342.2)$ & $430.2(385.1)$ & $552.8(457.5)$ & 0.031 \\
\hline OA versus vildagliptin & $655.2(539.2)$ & $992.5(888.7)$ & $747.5(659.4)$ & 0.012 \\
\hline Other drugs & 291.1 (194.I) & $202.3(155.3)$ & $266.7(177.3)$ & 0.597 \\
\hline Specialized care costs & $310.3(442.6)$ & $245.4(287.8)$ & $292.6(407)$ & 0.026 \\
\hline Days of hospitalization & I7.9 (I84.9) & $8.3(64.4)$ & I5.3 (I6I.2) & 0.405 \\
\hline Medical visits & $261(379.6)$ & $201.9(25 \mid .3)$ & $244.8(350.1)$ & 0.018 \\
\hline Emergency room visits & $31.5(64)$ & $35.3(71.2)$ & $32.5(66.1)$ & 0.422 \\
\hline Health costs & $2,684.9(1,456.5)$ & $2,517.5(1,173.2)$ & $2,639.1(1,386.2)$ & 0.041 \\
\hline Adjusted costs model* & & & Difference & \\
\hline Primary care costs & $2,383.7$ & $2,294.5$ & -89.2 & 0.290 \\
\hline $95 \% \mathrm{Cl}$ & $2,297.6-2,469.8$ & $2,153.3-2,435.7$ & & \\
\hline Specialized care costs & 315.3 & 249.5 & -65.9 & 0.028 \\
\hline $95 \% \mathrm{Cl}$ & $284.8-345.9$ & 199.3-299.6 & & \\
\hline Health costs & $2,699.1$ & $2,544.0$ & -155.1 & 0.044 \\
\hline $95 \% \mathrm{Cl}$ & $2,602.2-2,795.9$ & $2,385 . I-2,702.8$ & & \\
\hline
\end{tabular}

Notes: Values expressed as the mean (standard deviation). *Analysis of covariance model, the contrasts are based on comparisons of linearly independent pairs among the estimated marginal means.

Abbreviations: $\mathrm{OA}$, oral antidiabetics, includes sulfonylureas and glitazones; $\mathrm{Cl}$, confidence interval. 
needed to reinforce the consistency of these results, it seems clear that the role of DPP-4 inhibitors (eg, vildagliptin) in the therapeutic armamentarium for T2DM is evolving rapidly, although long-term data evaluating their effect on metabolic control are lacking. ${ }^{24,25}$ The available evidence indicates that a direct association between compliance and control is beyond doubt. ${ }^{6,21,23}$

Vildagliptin-treated patients had lower health care costs and used fewer health care resources. The few published studies available show that the higher the compliance and metabolic control in these patients, the lower the risk of hospitalization. A review by Breitscheidel et $\mathrm{al}^{26}$ concluded that improving compliance may result in a reduction of total health care costs in T2DM. In seven studies, compliance was inversely associated with total health care costs, and costs were lower because of fewer days of hospitalization. However, the variability in the studies reviewed was high, making comparison of the results difficult. Overall, our results are consistent with those studies, ${ }^{27}$ and again highlight the association between fewer episodes of hypoglycemia and less use of health care resources. ${ }^{28-30}$

Our results show lower rates of CVE and renal failure in vildagliptin-treated patients. Various studies in patients with type 1 or type 2 diabetes mellitus ${ }^{6-8,19,20}$ have shown that good metabolic control, represented by lower $\mathrm{HbA}_{1 \mathrm{c}}$ values, leads to significant improvement in the incidence and evolution of microangiopathic complications, and that this benefit persists for years, even when metabolic control worsens. However, evolution of macrovascular complications does not seem so dependent on achieving an acceptable level of $\mathrm{HbA}_{1 \mathrm{c}}$ as on the type of treatment used and the presence or absence of hypoglycemia. Given the close relationship between certain microangiopathies (principally nephropathy) and CVE, it is logical to consider that good metabolic control would have a positive influence, but with a lower intensity than the control of other risk factors, such as dyslipidemia and hypertension. ${ }^{6,8,28}$ In our study, these results are surprising, given that there is no scientific evidence of this available to date from clinical trials. The cardiovascular benefit of vildagliptin could be interpreted as a random bias due to the study design. ${ }^{31}$

The possible limitations of this research include categorization of the disease, the potential bias of patient classification, selection of therapeutic groups, and operating costs, which depend on the computerized data systems available. Therefore, our study has the limitations inherent in observational retrospective studies, including under-reporting or possible variability of patients and professionals.
This type of design is not without bias (including factors not taken into account, such as the socioeconomic, cultural, or educational level, as well as pharmacological doses ingested or their therapeutic appropriateness) that should be minimized. The main limitation of the study is the selection bias arising from the physician being responsible for administering one or the other drug, for whatever reason, and the results should be interpreted with caution. Another limitation relates to the extent of hypoglycemia, given that we only identified episodes in which the patient required medical treatment and this was documented, so there may have been undiagnosed cases. Patients treated with vildagliptin had a lower rate of renal events during follow-up. The absence of data for single-treatment metformin or vildagliptin and is needed for comparison (monotherapy) and should also be interpreted as a limitation of the study. Further, glucagon-like peptide-1 levels and their correlation with glucose or insulin levels in our subjects are unclear. Another limitation of the study was not considered a confounding variable dosage of drugs.

Future research will be needed to include studies of cost effectiveness and collection of data from other health care organizations. Overall, our results are consistent with the recommendations of the Institute for Quality and Efficiency in Health Care. ${ }^{32}$ The measure of effectiveness (ie, economic evaluation) should be based on a set of health interventions, not just on the price of a drug. In conclusion, patients receiving vildagliptin in combination with metformin showed better compliance and metabolic control and lower rates of hypoglycemia than patients treated with metformin and other oral antidiabetics, resulting in lower health care costs for the national health system.

\section{Author contributions}

ASM conceived of and designed the manuscript. Data were collected by ASM and RNA. ASM performed the statistical analysis. Both authors participated in interpretation of the data, and in the drafting, revision, and approval of the final manuscript.

\section{Disclosure}

This study was funded by Novartis. ASM was paid by Novartis to develop the manuscript. The statistical analysis was performed by ASM and funded by Novartis. The other author reports no competing interests in this work. Novartis had no role in the study design, data collection or analysis, the decision to publish, or preparation of the manuscript. 


\section{References}

1. Working Group Diabetes Mellitus and Cardiovascular Disease of the Spanish Society of Diabetes. Diabetes mellitus and cardiovascular risk. Recommendations of the Working Group of Diabetes Mellitus and Cardiovascular Disease of the Spanish Diabetes Society 2009. Endocrinol Nutr. 2010;57:220-226.

2. Mata M, Antoñanzas F, Tafalla M, Sanz P. [The cost of type 2 diabetes in Spain. CODE-2 study]. Gac Sanit. 2002;16:511-520. Spanish.

3. González P, Faure E, Del Castillo A; Working Group for the Study of the Cost of Diabetes. [Cost of diabetes mellitus in Spain]. Med Clin (Barc). 2006;127:776-784. Spanish.

4. Rosado Martín J, Martínez López MÁ, Mantilla Morató T, et al. MAPA. [Prevalence of diabetes in an adult population in the region of Madrid (Spain). The Madrid Cardiovascular Risk study]. Gac Sanit. 2012;26:243-250. Spanish.

5. Soriguer F, Goday A, Bosch-Comas A, et al. Prevalence of diabetes mellitus and impaired glucose regulation in Spain: the Di@bet.es Study. Diabetologia. 2012;55:88-93.

6. Menéndez Torre E, Lafita Tejedor J, Artola Menéndez S, et al. [Recommendations for the pharmacological treatment of hyperglycemia in type 2 diabetes. Working Group for Consensus and Clinical Guidelines of the Spanish Diabetes Society]. Rev Clin Esp. 2011;211:147-155. Spanish.

7. Inzucchi SE, Bergenstal RM, Buse JB, et al; American Diabetes Association (ADA) and the European Association for the Study of Diabetes (EASD). Management of hyperglycemia in type 2 diabetes: a patient-centered approach: position statement of the American Diabetes Association (ADA) and the European Association for the Study of Diabetes (EASD). Diabetes Care. 2012;35:1364-1379.

8. Puigdevall Gallego V, Laudo Pardos C, del Río Mayor MJ, Velasco Martín A. New drugs for the treatment of type-2 diabetes. Rev Clin Esp. 2000;200:151-156.

9. The ADVANCE Collaborative Group. Intensive blood glucose control and vascular outcomes in patients with type 2 diabetes. $N$ Engl J Med. 2008;358:2560-2572.

10. Nathan DM, Buse JB, Davidson MB, et al. Medical management of hyperglycemia in type 2 diabetes: a consensus algorithm for the initiation and adjustment of therapy. A consensus of the American Diabetes Association and the European Association for the Study of Diabetes. Diabetes Care. 2009;32:193-203.

11. Dejager S, Schweizer A, Foley JE. Evidence to support the use of vildagliptin monotherapy in the treatment of type 2 diabetes mellitus. Vasc Health Risk Manag. 2012;8:339-348.

12. Cai L, Cai Y, Lu ZJ, Zhang Y, Liu P. The efficacy and safety of vildagliptin in patients with type 2 diabetes: a meta-analysis of randomized clinical trials. J Clin Pharm Ther. 2012;37:386-398.

13. Lamberts H, Wood M, Hofmans-Okkes IM, editors. The International Classification of Primary Care in the European Community. With a Multi-Language Layer. Oxford, UK: Oxford University Press; 1993.

14. World Health Organization. The Anatomical Therapeutic Chemical Classification System; Geneva, Switzerland: World Health Organisation; 1991.

15. Charlson ME, Pompei P, Ales KL, Mackenzie CR. A new method of classifying prognostic comorbidity in longitudinal studies: development and validation. J Chronic Dis. 1987;40:373-383.

16. Weiner JP, Starfield BH, Steinwachs DM, Mumford LM. Development and application of a population-oriented measure of ambulatory care case-mix. Med Care. 1991;29:452-472.
17. Thompson SG, Barber JA. How should cost data in pragmatic randomised trials be analysed? BMJ. 2000;320:1197-1200.

18. Sinclair A, Morley JE, Rodriguez-Mañas L, et al. Diabetes mellitus in older people: position statement on behalf of the International Association of Gerontology and Geriatrics (IAGG), the European Diabetes Working Party for Older People (EDWPOP), and the International Task Force of Experts in Diabetes. J Am Med Dir Assoc. 2012;13:497-502.

19. Halimi S, Raccah D, Schweizer A, Dejager S. Role of vildagliptin in managing type 2 diabetes mellitus in the elderly. Curr Med Res Opin. 2010;26:1647-1656.

20. Gaede P, Lund-Andersen H, Parving HH, Pedersen O. Effect of a multifactorial intervention on mortality and in type 2 diabetes. $N$ Engl J Med. 2008;358:580-591.

21. Márquez Contreras E, Martell Claros N, Gil Guillén V, et al; Compliance Working Group of the Association of Spanish Society of Hypertension and Spanish League for the Fight Against Arterial Hypertension (SEH-LELHA). [Therapeutic non-compliance with insulin in the treatment of diabetes mellitus 2]. Aten Primaria. 2012;44:74-81. Spanish.

22. Cramer JA, Benedict A, Muszbek N, Keskinaslan A, Khan ZM. The significance of compliance and persistence in the treatment of diabetes, hypertension and dyslipidaemia: a review. Int J Clin Pract. 2008;62:76-87.

23. Jermendy G, Wittmann I, Nagy L, et al. Persistence of initial oral antidiabetic treatment in patients with type 2 diabetes mellitus. Med Sci Monit. 2012;18:CR72-CR77.

24. Guillausseau PJ. Impact of compliance with oral antihyperglycemic agents on health outcomes in type 2 diabetes mellitus: a focus on frequency of administration. Treat Endocrinol. 2005;4:167-175.

25. Scheen AJ. DPP-4 inhibitors in the management of type 2 diabetes: a critical review of head-to-head trials. Diabetes Metab. 2012;38:89-101.

26. Breitscheidel L, Stamenitis S, Dippel FW, Schöffski O. Economic impact of compliance to treatment with antidiabetes medication in type 2 diabetes mellitus: a review paper. J Med Econ. 2010;13:8-15.

27. Wild $H$. The economic rationale for adherence in the treatment of type 2 diabetes mellitus. Am J Manag Care. 2012;18(Suppl 3):S43-S48.

28. Liu S, Zhao Y, Hempe JM, Fonseca V, Shi L. Economic burden of hypoglycaemia in patients with Type 2 diabetes. Expert Rev Pharmacoecon Outcomes Res. 2012;12:47-51.

29. Stamataros G, Schneider SH. Vildagliptin in the treatment of type 2 diabetes mellitus. Expert Opin Pharmacother. 2011;12:1967-1973.

30. Genovese S, Tedeschi D. Effects of vildagliptin/metformin therapy on patient-reported outcomes: work productivity, patient satisfaction, and resource utilization. Adv Ther. 2013;30:152-164.

31. Strain WD, Lukashevich V, Kothny W, Hoellinger MJ, Paldánius PM. Individualised treatment targets for elderly patients with type 2 diabetes using vildagliptin add-on or lone therapy (INTERVAL): a 24 week, randomised, double-blind, placebo-controlled study. Lancet. 2013;382:409-416.

32. Elisabeth Müller V, Schmacke N, Kolip P, Berger B. [Desirable, unfamiliar and in need of communication - the evidence-based decision aid of the Institute for Quality and Efficiency in Health Care (IQWiG)]. Z Evid Fortbild Qual Gesundhwes. 2012;106:290-294. German. 


\section{Publish your work in this journal}

Drug Design, Development and Therapy is an international, peerreviewed open-access journal that spans the spectrum of drug design and development through to clinical applications. Clinical outcomes, patient safety, and programs for the development and effective, safe, and sustained use of medicines are a feature of the journal, which

has also been accepted for indexing on PubMed Central. The manuscript management system is completely online and includes a very quick and fair peer-review system, which is all easy to use. Visit http://www.dovepress.com/testimonials.php to read real quotes from published authors.

Submit your manuscript here: http://www.dovepress.com/drug-design-development-and-therapy-journal 